\title{
Biomedical applications of Durio zibethinus extract mediated gold nanoparticles as antimicrobial, antioxidant and anticoagulant activity
}

\begin{abstract}
An eco-friendly and efficient method has been used for green synthesis of stable gold nanoparticles (Au NPs) using Durio zibethinus extract as a reducing and capping agent. The biologically produced nanoparticles were characterized by UV-Vis, XRD, SEM, EDAX and TEM analysis. The elemental composition of Au NPs was reported by EDAX spectral analysis. The bio-reduced Au NPs exhibited almost spherical. Increasing applications of NPs especially metallic nanoparticle plays an important role. Gold is one of the most useful metallic nanoparticles. Au NPs having unique physiochemical characteristics and wide usage in different field applications. Besides, antibacterial, antioxidant and anticoagulant properties of Au NPs were studied. It is proved that Au NPs synthesized using natural reducing agents (plant leaves, route, seeds, pulp, stem, etc.) are eco-friendly, inexpensive, have good anti-microbial activities against micro-organisms. This study established a synthesis of Au NPs using Durio zibethinus extract as a viable green route approach, with remarkable antimicrobial, antioxidant and anticoagulant activities. As far as we know, this is the first report of the use of Durio zibethinus extract to synthesize Au NPs.
\end{abstract}

Keywords: Durio zibethinus, gold nanoparticles, antimicrobial, antioxidant, anticoagulant
Volume 5 Issue 5 - 2019

\author{
Vinay S P,' Udayabhanu, ${ }^{2}$, Nagaraju G, ${ }^{2}$ \\ Hemasekhar $\mathrm{B}^{3}$ Chandrappa C $\mathrm{P}^{3}$ \\ Chandrasekhar $\mathrm{N}$ \\ Department of Chemistry, Shridevi Institute of Engineering and \\ Technology, India \\ 2Department of Biotechnology, Shridevi Institute of Engineering \\ and Technology, India
}

\begin{abstract}
Correspondence: Chandrasekhar N, Research and Development Center, Department of Chemistry, Shridevi Institute of Engineering and Technology, Tumakuru - 572106, Karnataka, India, Email chandruharshu@gmail.com
\end{abstract}

Received:September 25, 2019 | Published: October II, 2019

\section{Introduction}

Nanotechnology is an innovative branch of science deals with the formation, processing, and applications of nanomaterials. Nanoscale metal oxide semiconductor materials have been widely used in research due to their distinctive properties. ${ }^{1}$ Efforts are being made to develop simple, nontoxic, biocompatible and eco-friendly nanomaterials through the green chemistry approach. ${ }^{2-7}$ Different parts of plants are extensively exploited for the synthesis of various nanoparticles where the metal salt solution is mixed with plant extract with varying reaction conditions and stirred to reduce the metal, leading to nucleation and synthesis of respective metal nanoparticles. ${ }^{8-10} \mathrm{Metal} /$ Metal oxide nanoparticles $\mathrm{Ag}, \mathrm{Au}, \mathrm{ZnO}, \mathrm{MgO}$ have good antibacterial activities. The study of the antioxidant property of nanoparticles has become one of the significant basic studies in pharmaceutical science and nanoscience. ${ }^{11-14} \mathrm{An}$ antioxidant is a compound that delays or prevents the oxidation of an oxidizible species. Oxidative stress was induced by ROS produced in the body, is one of the main factors of current slow killer diseases, that the population suffering from, like diabetes, cancer, cardiovascular neurological inflammatory viral diseases and digestive disorders. ${ }^{15}$ Durio zibethinus is the most common tree species in the genus Durio that are known as durian and has edible fruit also known as durian. Durio is exceptionally rich in polyphenols such as flavanol monomers and procyanidin oligomers. Besides phenolic compounds, other chemicals like methylxanthine and anthocyanins in Durio zibethinus might influence the anti-oxidant capacity. ${ }^{16}$ Polyphenols or phenolics have attracted the attention of researchers over the world because of their physical and biological functions, including antioxidant, anticarcinogenic, anti-allergic, antiatherogenic and antidiabetic assays. All these desirable biological potentials of the chemical components of Durio zibethinus motivated the current examination into its nano-biotechnological possible in green-chemistry. In this examination, we report for the first time the synthesis of Au NPs using Durio zibethinus seeds extract as a capping and reducing agents, as well as a demonstration of its anti-microbial, antioxidant and anti-coagulant assays.

\section{Experimental}

\section{Collection and processing and preparation of Durio zibethinus extract}

Durio zibethinus seeds were extracted from fresh, methodically washed Durio fruits obtained from Bangalore Fruit market, Electronic City, Bengaluru, India. The Durio seeds were first washed into distilled water before air drying for 7 to 10 days at ambient temperature. They were later de-shelled and milled into powder with the aid of a mixer grinder (Figure 1). Durio seeds extract was obtained following the procedures of Vinay SP et al..$^{17}$ and later the final clean dry extract which was stored at $4^{\circ} \mathrm{C}$ for further use.

\section{Preparation of Au NPs}

To synthesize Au NPs, 60mg of Durio zibethinus seeds extract was added to $90 \mathrm{ml}$ of $5 \mathrm{mM}$ Chloroauric acid (HAuCl4) at ambient temperature, stirred continuously for $1 \mathrm{~h}$ in magnetic stirrer to mix the metal precursor completely and kept for reflux with vigorous stirring at $97^{\circ} \mathrm{C}$ for 5 to $6 \mathrm{~h}$. The reaction mixture was allowed to under slow reduction into $\mathrm{Au}$ NPs for $24 \mathrm{~h}$ to complete the bioreduction process (Figure 2). Further, the obtained solid material was purified by repeated centrifugation at $4000 \mathrm{rpm}$ for $10 \mathrm{~min}$. Finally, the synthesized $\mathrm{Au}$ nanoparticles were dried in a hot air oven at $60^{\circ} \mathrm{C} 10$ to $12 \mathrm{~h}$ and stored in airtight vials.

\section{Antibacterial assay}

Antibacterial activity was screened against Gram -ve bacteria ( $P$. desmolyticum) and Gram +ve bacteria ( $S$. aureus) bacteria 
(NCIM- 5022) by disc diffusion method. Diverse concentrations of $\mathrm{Au}$ nanoparticles (1500 and $1000 \mu \mathrm{g} /$ well) were used to assess the activity of the nanoparticles. Ciprofloxacin $(5 \mu \mathrm{g} / 50 \mu \mathrm{L})$ was used standard and incubated these Petri plates at $37^{\circ} \mathrm{C}$ for $24 \mathrm{~h}$. These Petri plates the developed zone of inhibition of every disc was measured in millimeter.

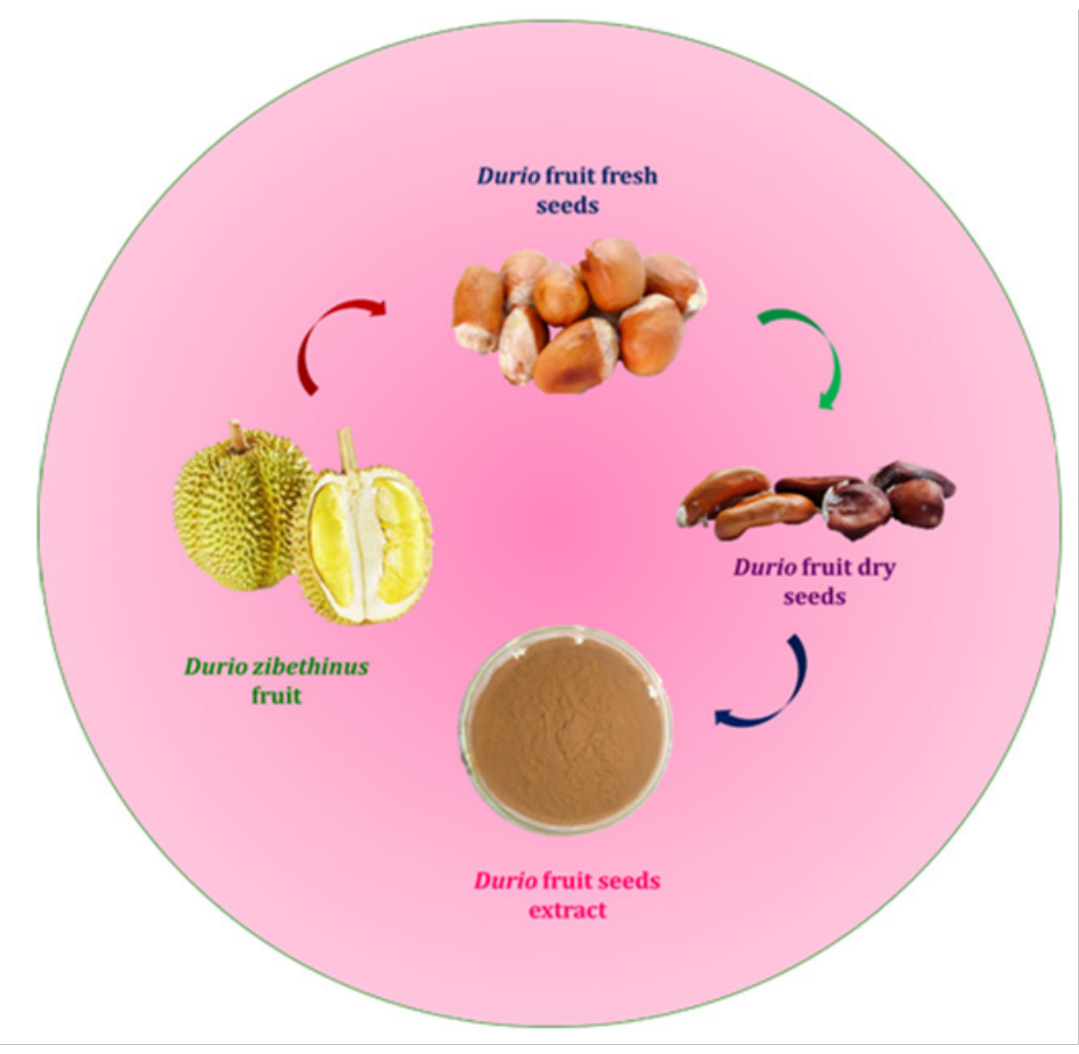

Figure I Schematic representation for the preparation of Durio zibethinus seeds extract for synthesis of Au NPs.

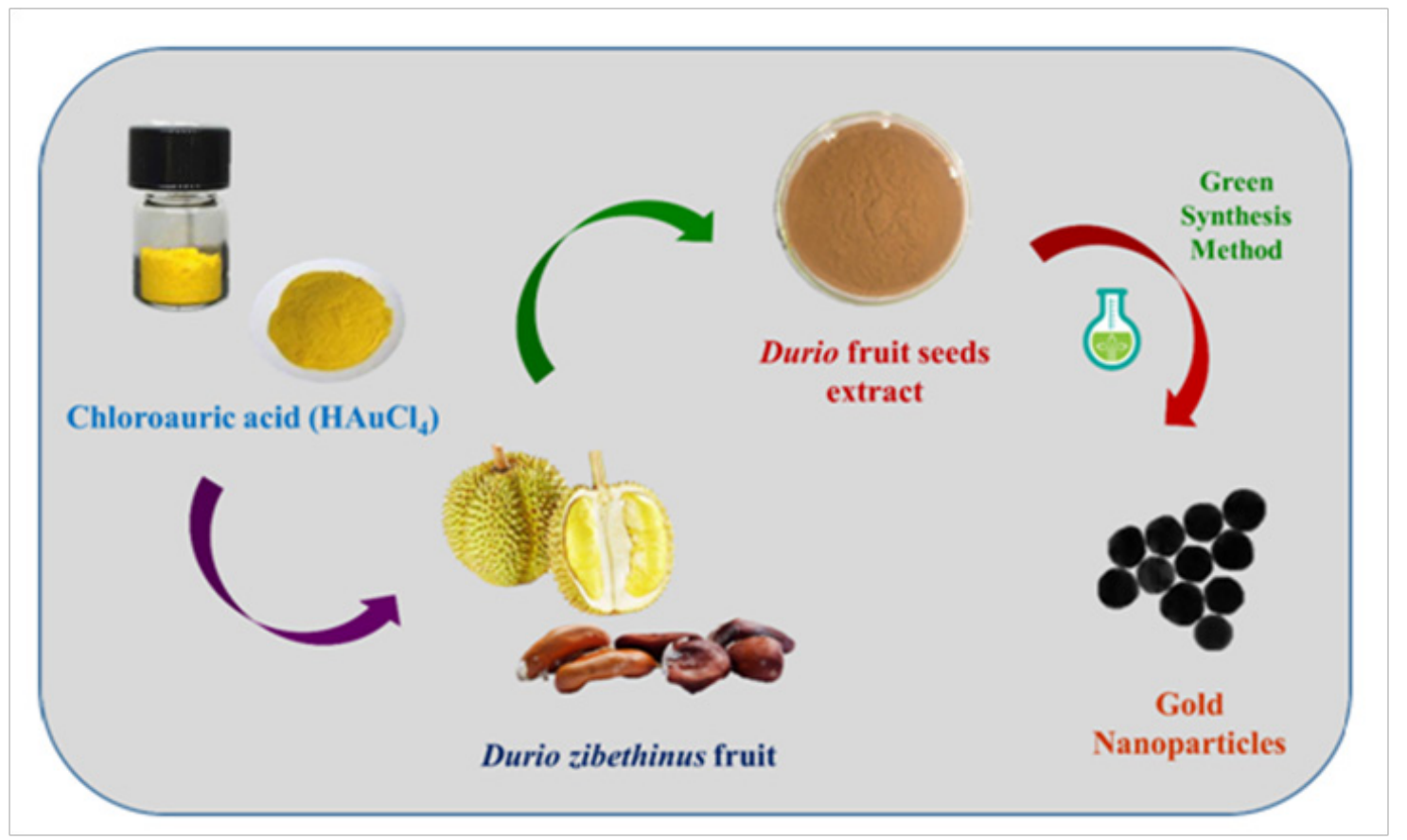

Figure 2 Schematic representation for the synthesis of Au NPs. 


\section{Antioxidant activity}

Antioxidant activity was carried out by 1,1-Diphenyle-2picrylhydrazyl assay by the Brand Williams technique. DPPH is a stable free radical with purple color having an absorption maximum at $520 \mathrm{~nm}$. In the presence of an antioxidant which can donate an electron to DPPH radical for inhibiting the activity of DPPH molecule. This results in a change in absorbance at $520 \mathrm{~nm}$. The $\%$ inhibition was calculated by the equation IC50 value was determined by plotting the line at $50 \%$ inhibition (y-axis) to the concentration of the test sample (x-axis).

$$
\% \text { Inhibition }=\frac{\text { Absorbance }(\text { control })-\text { Absorbance }(\text { Test })}{\text { Absorbance }(\text { control })} \times 100 \ldots
$$

\section{Anticoagulant activity}

The anticoagulant activity of Au NPs was investigated by mixing blood freely collected (goat and sheep blood) in meat stall near S.I.E.T college, donated (human blood) by a healthy volunteer (collected from S.I.E.T Medical college, Tumkur) with an equal volume of $170 \mu \mathrm{g} / \mathrm{ml}$ of NPs. The control samples were set up using the EDTA solution. The reaction mixtures were held at ambient temperature $\left(30 \pm 2^{\circ} \mathrm{C}\right)$ for $1 \mathrm{~h}$ and then observed macroscopically on the slide, and microscopically for the formation of blood clots.

\section{Results and discussion}

\section{XRD Study}

Figure 3 Shows the XRD patterns of Au NPs. The XRD peak positions were consistent with the $\mathrm{Au}$ and sharp peaks of XRD indicate the crystalline structure. Intense peaks at $2 \theta=38^{\circ}, 44^{\circ}, 64^{\circ}$ and $77^{\circ}$ that could be indexed as (311), (220), (200) and (111) reflections, indicating the f.c.c. structure of Au nanoparticles. ${ }^{18}$ These are in good agreement with the standard JCPDS card No- 04-0784.

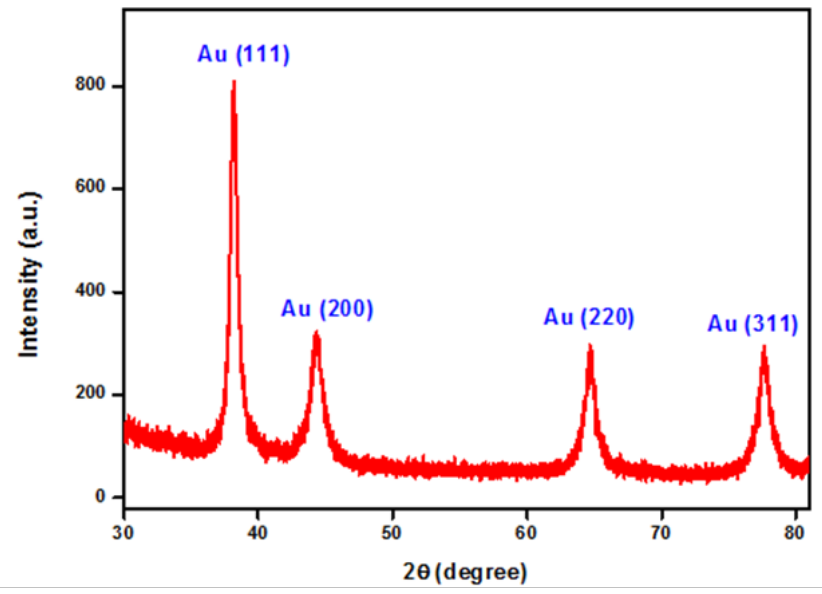

Figure 3 XRD spectrum of Au NPs.

\section{UV-Vis spectroscopy}

The study of absorption band with a peak shows in around 530$540 \mathrm{~nm}$ discovered to SPR is exhibited. The gold nanoparticles absorption peak appeared the $538 \mathrm{~nm}$ this could be proved (Figure 4). The prepared gold nanoparticles had spherical morphology in nature.

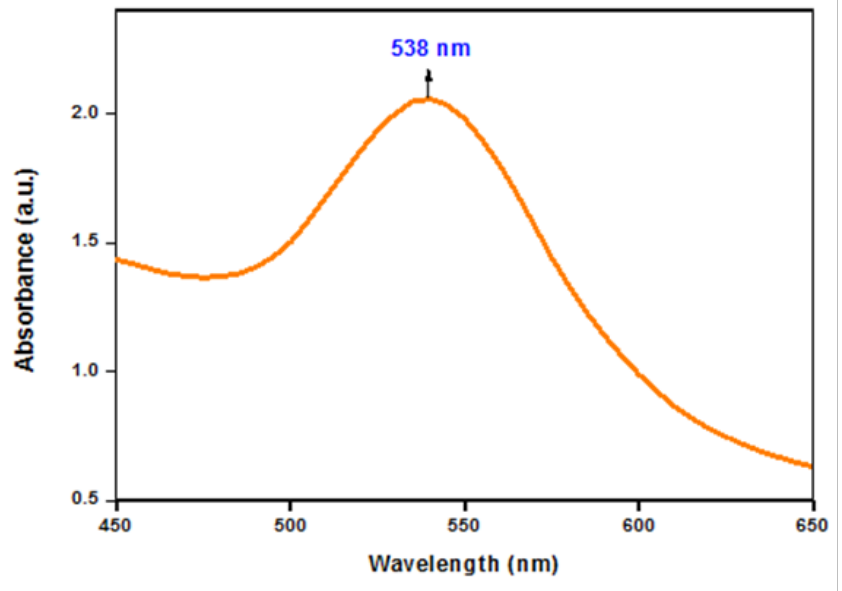

Figure 4 UV-Vis spectrum of Au NPs.

\section{SEM and EDAX analysis}

The SEM images of as-synthesized Au nanoparticles were shown in Figure 5A \& 5B. The image reveals that Au NPs are uniform spherical like structures with agglomeration. The EDAX spectrum shows the presence of strong gold $\mathrm{(Au}$ ) peaks indicating the purity of the synthesized material Figure 5C. ${ }^{19}$
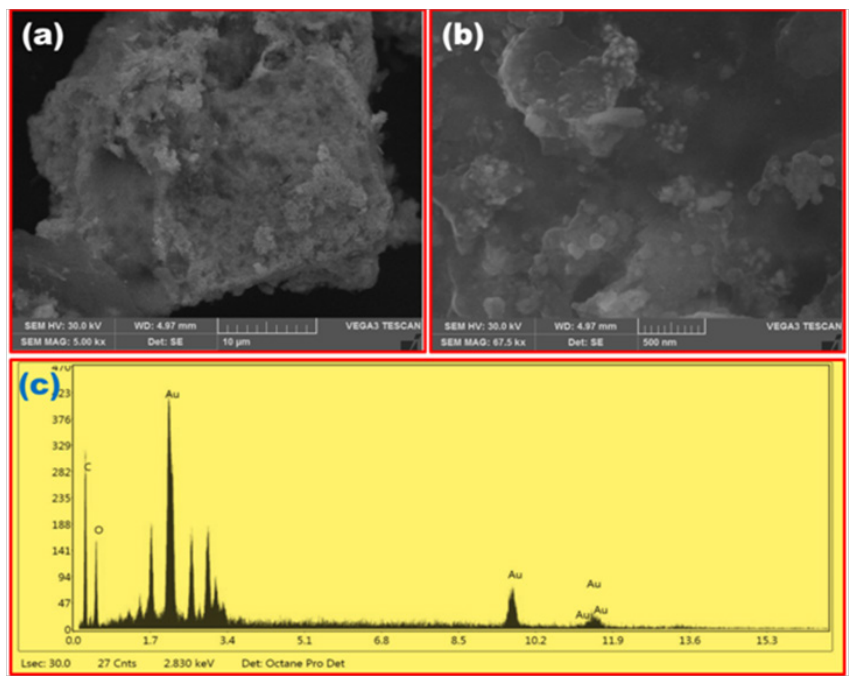

Figure 5 (A), (B) SEM images, (C) EDAX spectrum of Au NPs.

\section{TEM analysis}

The Au NPs were mostly spherical in shapes and ranged from 20$50 \mathrm{~nm}$ with an average size of $35.71 \mathrm{~nm}$ as shown in Figure 6.

\section{Antibacterial activity}

The anti-bacterial assay of $\mathrm{Au}$ nanoparticles was determined against human pathogenic bacteria comprising gram -ve bacteria (P. desmolyticum) and gram + ve bacteria (S. aureus), as shown in Figure 7. The dimensions of the zones of inhibition obtained with the pathogens are presented in Table 1. 

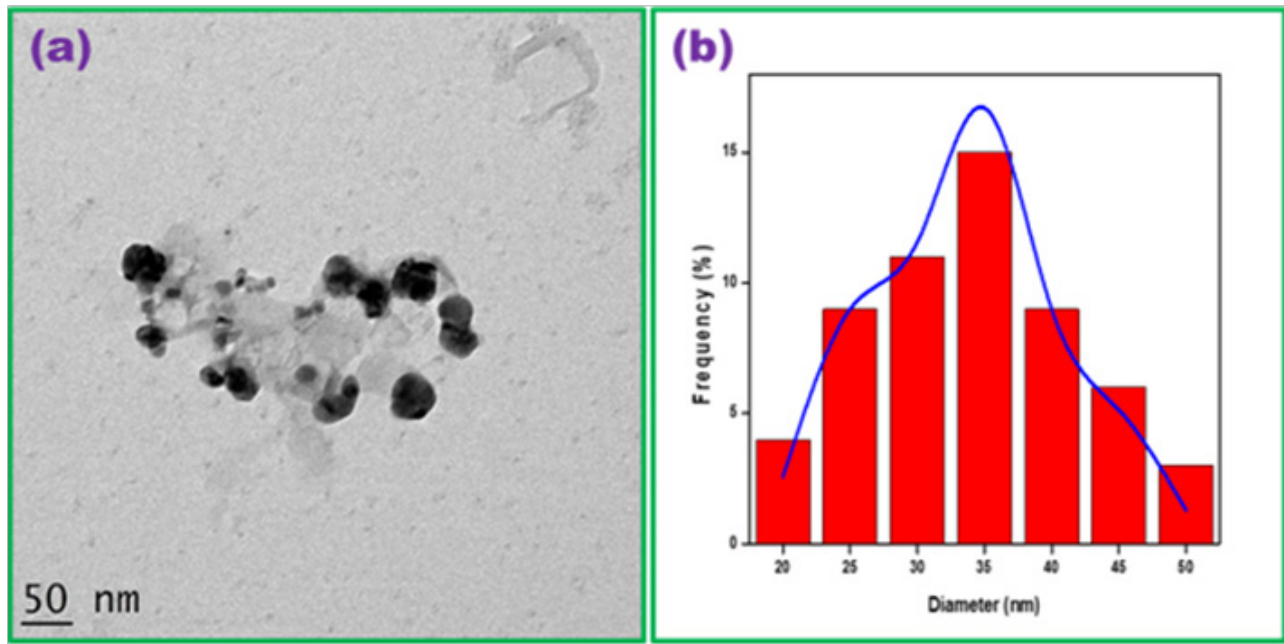

Figure 6 (A) TEM image, (B) Histogram spectrum of Au NPs.

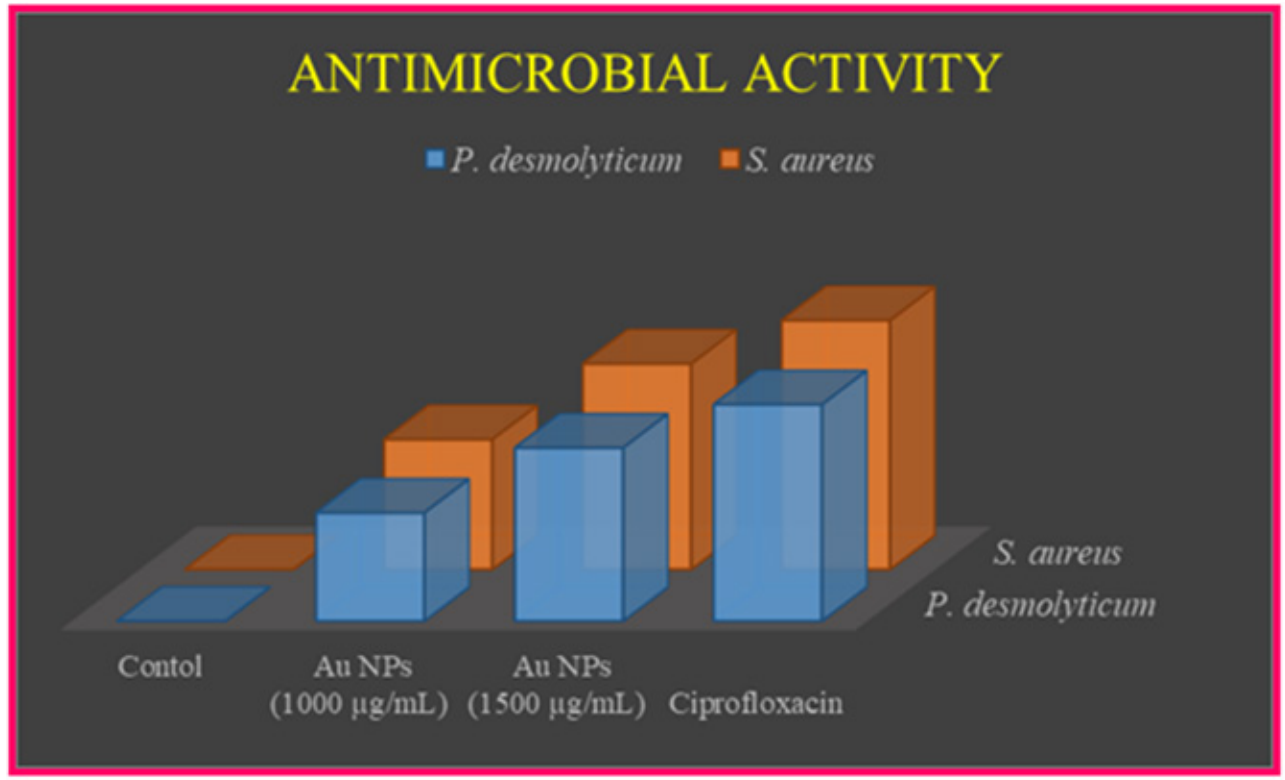

Figure 7 Bar diagram of inhibition zone of antibacterial activity of Au NPs.

Table I Antibacterial activity of Au NPs against pathogenic bacteria

\begin{tabular}{|c|c|c|c|}
\hline SI. No & Treatment & $\begin{array}{l}\text { Pseudomonas } \\
\text { desmolyticum } \\
\text { (mean } \pm \text { SE) }\end{array}$ & $\begin{array}{l}\text { Staphylococcus } \\
\text { aureus } \\
\text { (mean } \pm \text { SE) }\end{array}$ \\
\hline I & Control & NA & NA \\
\hline 2 & Au NPs $(1000 \mu \mathrm{g} / \mathrm{mL})$ & $10.47 \pm 0.30$ & $12.50 \pm 0.29$ \\
\hline 3 & Au NPs $(1500 \mu g / m L)$ & $16.50 \pm 0.30$ & $19.50 \pm 0.29$ \\
\hline 4 & Ciprofloxacin $(5 \mu \mathrm{g} / \mathrm{mL})$ & $20.63 \pm 0.17$ & $23.17 \pm 0.44$ \\
\hline \multicolumn{4}{|c|}{$\begin{array}{l}\text { Values are the mean } \pm S E \text { of inhibition zone in } \mathrm{mm} \text {. NA Symbols represent no antibacterial activity wa } \\
\text { found in this work. }\end{array}$} \\
\hline
\end{tabular}




\section{Antioxidant activity}

DPPH a stable free radical with a characteristic absorption at 517 to $520 \mathrm{~nm}$, was used to study the radical scavenging activity of Au NPs. The decrease in absorption is considered as a measure of the extent of radical scavenging. The percentage of inhibition or scavenging of free radicals was determined. The Au NPs were inhibiting the DPPH free radical scavenging activity with IC50 value of $370 \mu \mathrm{g} / \mathrm{mL}$ (Figure 8).

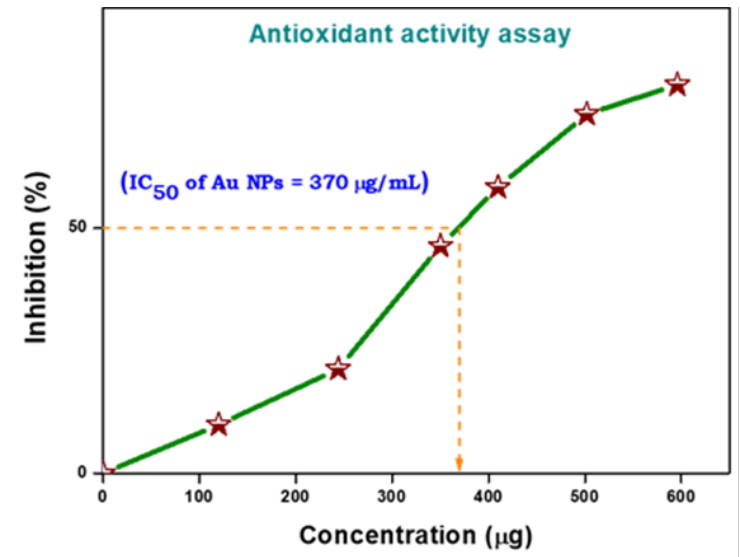

Figure 8 Percentage inhibition of DPPH radical.

\section{Anticoagulant Assay}

The Au nanoparticles prevented the coagulation of human $(92.1$ $\%)$, goat $(87.5 \%)$ and sheep $(82.9 \%)$ type of blood in vitro (Figures 9-11), and remained essentially the morphology of RBCs as obtained in the fresh blood and that which was collected in the EDTA coated bottles. ${ }^{20}$ The control samples treated with Durio zibethinus seeds extract and $\mathrm{HAuCl} 4$ solution failed to prevent the coagulation of blood. Additionally, a current study by Musibau et al. ${ }^{21}$ reported the upgrading of anticoagulant activities of Ag NPs bio-synthesized by the Cocoa bean extract. The increasing evidence suggests that MNPs may have a possible application in the control and management of blood coagulation disorders.

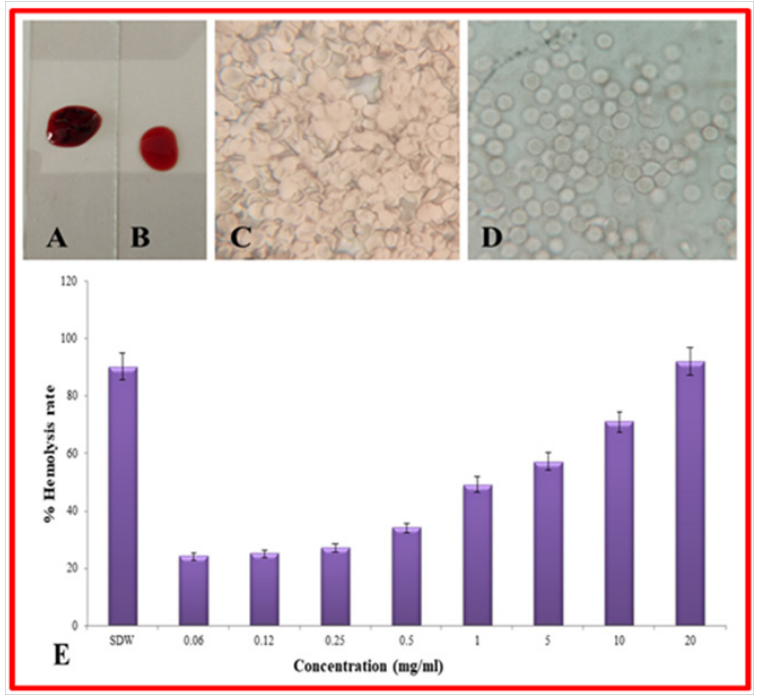

Figure 9Au NPs stability and coagulant activity on Human blood. (A) Blood clot, (B) Blood treated with Au NPs, (C) Optical microscopy image of blood clot, (D) Optical microscopy image of blood treated with Au NPs, (E) Au NPs stability.

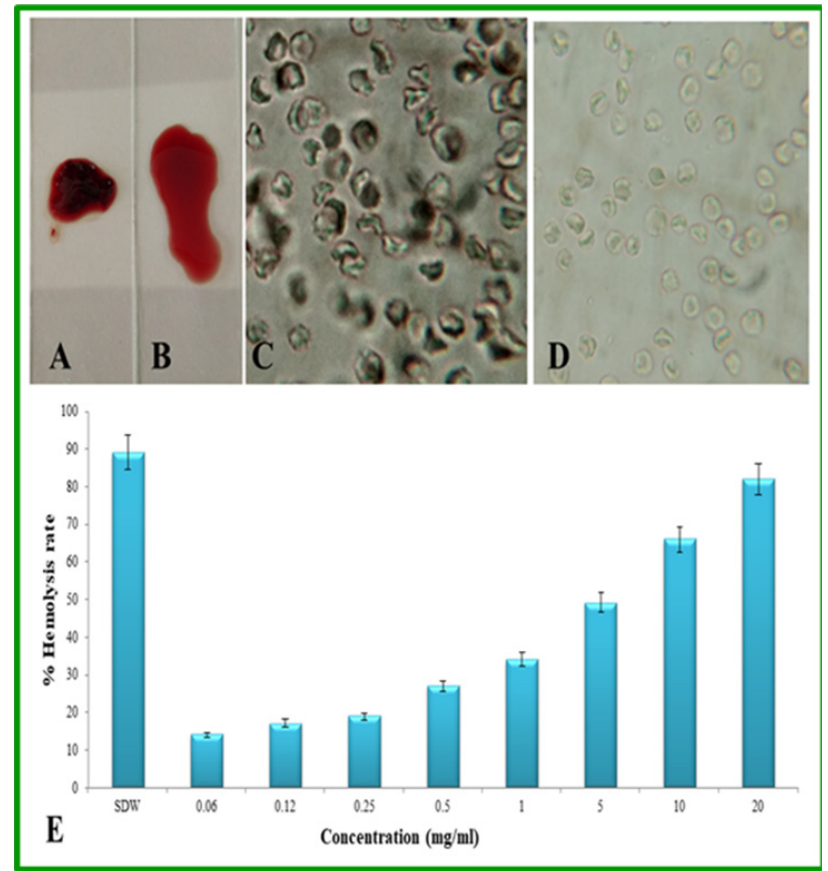

Figure 10 Au NPs stability and coagulant activity on Goat blood. (A) Blood clot, (B) Blood treated with Au NPs, (C) Optical microscopy image of blood clot, (D) Optical microscopy image of blood treated with Au NPs, (E) Au NPs stability.

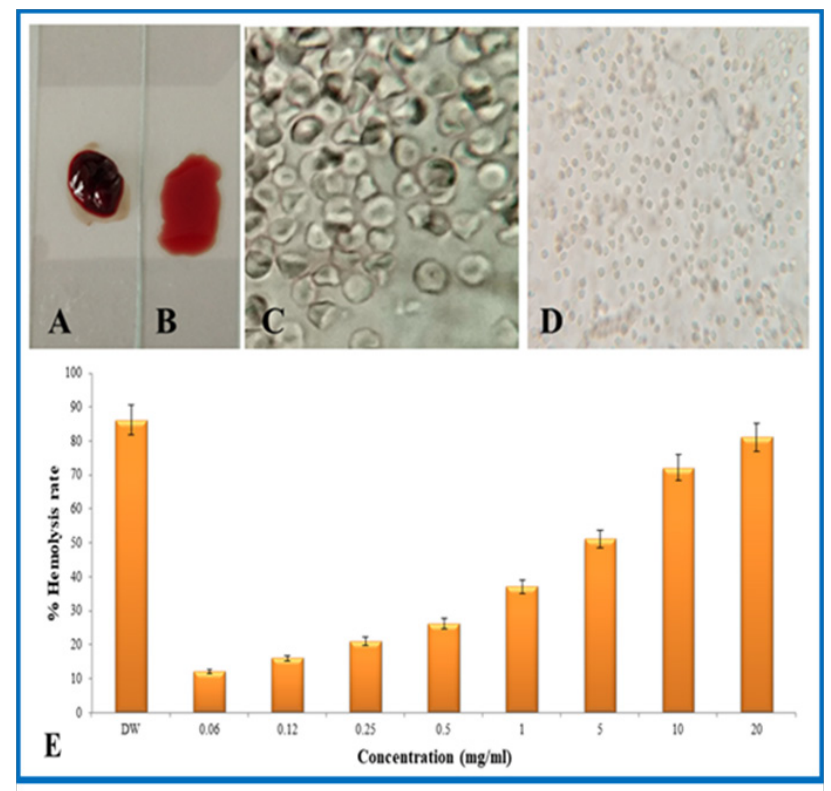

Figure I IAu NPs stability and coagulant activity on Sheep blood. (A) Blood clot, (B) Blood treated with Au NPs, (C) Optical microscopy image of blood clot, (D) Optical microscopy image of blood treated with Au NPs, (E) Au NPs stability.

\section{Conclusion}

In the present work, the green synthesis method was employed to obtain Au NPs from the assistance of Durio zibethinus seeds extract as a reducing agent and capping agent. UV-Vis, XRD, SEM, EDAX and TEM techniques were utilized to characterize the as-synthesized 
nanoparticles. SEM and TEM images reveal that nanoparticles possess spherical. The average nanoparticles size was found to be $35 \mathrm{~nm}$. Au NPs exhibited important anti-bacterial assay against gram + ve and gram -ve bacterial strains. Au NPs exhibited outstanding antioxidant and anticoagulant activities. Overall, the green synthesized Au NPs will be useful in the biomedical and materials industries.

\section{Acknowledgments}

Udayabhanu thanks to CSIR, New Delhi, for Senior Research Fellowship (09/1204(0001)/2018-EMR-1). Dr. Chandrasekhar and Vinay thank Dr. M R Hulinaykar, Managing Trustee, Sri Shridevi Charitable Trust, and Shridevi Institute of Engineering and Technology for encouragement and support for research work. Dr. GN Thank DST Nanomission (SR/NM/NS1262/2013) for financial support.

\section{Conflicts of interest}

The authors declare that they have no conflict of interest.

\section{References}

1. Albrecht MA, Evans CW, Raston CL. Green chemistry and the health implications of nanoparticles. Green Chem. 2006;8:417-432.

2. Frattini A, Pellegri N, Nicastro D, et al. Effect of amine groups in the synthesis of Ag nanoparticles using aminosilanes. Mat Chem Phys. 2005;94:148-152.

3. Duran N, Marcato PD, De Souza GI, et al. Antibacterial effect of silver nanoparticles produced by fungal process on textile fabrics and their effluent treatment. J Biomed Nanotechnol. 2007;3:203-208.

4. Merga G, Wilson R, Lynn G, et al. Redox catalysis on naked silver nanoparticles. J Phys Chem C. 2007;111:12220-12226.

5. Guo JZ, Cui H, Zhou W, et al. Ag nanoparticle-catalyzed chemiluminescent reaction between luminol and hydrogen peroxide. $J$ Photochem Photobiol A Chem. 2008;193:89-96.

6. Kotthaus S, Gunther B, Hang R, et al. Study of isotropically conductive bondings filled with aggregates of nanosited Ag-particles. IEEE Trans Comp Pack Manuf Technol A. 1997;20:15-20.

7. Jiang H, Manolache S, Wong ACL, et al. Plasma-enhanced deposition of silver nanoparticles onto polymer and metal surfaces for the generation of antimicrobial characteristics. Journal of Applied Polymer Science. 2004;93(3):1411-1422.

8. Kumar V, Yadav SK. Plant mediated synthesis of silver and gold nanoparticles and their applications. J Chem Technol. Biotechnol. 2009;84:151-157.

9. Huang J, Li Q, Sun D, et al. Biosynthesis of silver and gold nanoparticles by novel sundried Cinnamomum camphora leaf. Nanotechnology. 2007;18:105-115.
10. Udayabhanu, Nagaraju G, Nagabhushana H, et al. Green, Nonchemical route for the synthesis of $\mathrm{ZnO}$ superstructures, Evaluation of its applications toward Photocatalysis, Photoluminescence, and Biosensing. Crystal Growth \& Design. 2016;16(12):6828-6840.

11. Casida JE, Quistad GB. Insecticide targets: learning to keep up with resistance and changing concepts of safety. Agricultural Chemistry and Biotechnology. 2005;43:185-191.

12. Logeswari P, Silambarasan S, Abraham J. Ecofriendly synthesis of silver nanoparticles from commerciallyavailable plant powders and their antibacterial properties. Scientia Iranica F . 2013;20(3):1049-1054.

13. Peter Logeswari, Sivagnanam Silambarasan, Jayanthi Abraham. Synthesis of silver nanoparticles using plants extract and analysis of their antimicrobial property. Journal of Saudi Chemical Society. $2015 ; 19: 311-317$.

14. Mehrdad forough, Khalil farhadi. Biological and green synthesis of silver nanoparticles. Turkish J Eng Env Sci. 2010;34:281 - 287.

15. Pushpa Agrawal, Karan Mehta, Pooja Vashisth, et al. Green Synthesis of Silver Nanoparticles and Their Application in Dental Filling Material. International Journal of Innovative Research in Science and Engineering Technology. 2014;3(6):13038-13052.

16. Arancibia-Avila P, Toledo F, Park YS, Jung ST, Kang SG, Heo BG, Lee SH, Sajewicz M, Kowalska T, Gorinstein S. Antioxidant properties of durian fruit as influenced by ripening. LWT-food Science and Technology. 2008;41(10):2118-2125.

17. Vinay SP, Udayabhanu, Nagaraju G, Chandrappa CP, et al. Rauvolfia tetraphylla (Devil Pepper)-Mediated Green Synthesis of Ag Nanoparticles: Applications to Anticancer, Antioxidant and Antimitotic. J Cluster Science. 2019;30:1-20.

18. Indramani Kumar, Moumita Mondal, Vadivel Meyappan, et al. Green one-pot synthesis of gold nanoparticles using Sansevieria roxburghiana leaf extract for the catalytic degradation of toxic organic pollutants. $J$ materresbull. 2019;29(4):1-23.

19. Hamelian M, Hemmati S, Varmira K, et al. Green synthesis, antibacterial, antioxidant and cytotoxic effect of gold nanoparticles using Pistacia Atlantica extract. Journal of the Taiwan Institute of Chemical Engineers. 2018;93:21-30

20. Kim HK, Choi MJ, Cha SH, et al. Earthworm extracts utilized in the green synthesis of gold nanoparticles capable of reinforcing the anticoagulant activities of heparin. Nanoscale research letters. 2013;8(1):542.

21. Azeez MA, Lateef A, Asafa TB, Yekeen TA, Akinboro A, Oladipo IC, Gueguim-Kana EB, Beukes LS. Biomedical applications of cocoa bean extract-mediated silver nanoparticles as antimicrobial, larvicidal and anticoagulant agents. Journal of Cluster Science. 2017;28(1):149-164. 